\title{
Prevalence of postpartum depression and associated factors among postnatal care attendees in Debre Berhan, Ethiopia, 2018
}

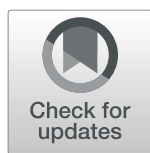

\author{
Abate Dargie Wubetu*, Nigus Alemnew Engidaw and Kefyalew Dagne Gizachew
}

\begin{abstract}
Background: Postpartum depression explains various groups of depressive symptoms and syndromes that can take place during the first 6 weeks following birth. The postpartum period is a critical time where both mild and severe mood disorders can occur. The familiar forms are baby blues and postpartum depression. Understanding the prevalence and associated factors of postpartum depression is mandatory for early detection and treatment.

Methods: Institution based cross-sectional study was conducted from 1st May to June 30, 2018. The study participants were eligible women who came to Debre Berhan referral hospital and health centers for postnatal care and vaccination service. The Edinburgh postnatal depression scale was used to assess postpartum depression. A systematic random sampling technique was used to collect the data after determining the skip fraction $(k=2)$. The collected data were coded and entered into Epi-info version 7 and transported to SPSS version 20 for analysis. Both bivariate and multivariate binary logistic regression were done to identify associated factors. During bivariate analysis, variables with $p$-value $<0.05$ were included in multivariate analysis. Odds ratios and their $95 \%$ confidence intervals were computed and variables with $p$-value less than 0.05 were considered to declare significantly associated factors (multivariate analysis).

Results: A total of 308 mothers who attended postpartum care we're included, which was a 100\% response rate. The prevalence of postpartum depression was found to be $15.6 \%(95 \% \mathrm{Cl}=11.7,19.8)$. Being widowed/widower, having poor social support, having a current hospitalized child, and experienced a death of family member or close relative were significantly associated with postpartum depression.

Conclusions: The prevalence of postpartum depression was lower than most studies done in different areas. Major life events and traumas are associated with an increased risk of postpartum depression. Health professionals should be aware of the mother's circumstances during the puerperium, they should initiate support to reduce the risk of depression in the postpartum period. Health care professionals working postpartum care clinics should give special attention to mothers who are widowed/widower, have poor social support, have a current hospitalized children, and experienced a death of family member or close relative.
\end{abstract}

Keywords: Prevalence, Magnitude, Puerperium, Depression, Morbidity, Ethiopia

\footnotetext{
* Correspondence: abebechbayne100@gmail.com; abatedargie@dbu.edu.et Department of Psychiatry, College of Health Science and Medicine, Debre Berhan University, P.O. Box 445, Debre Berhan, Ethiopia
}

(c) The Author(s). 2020 Open Access This article is licensed under a Creative Commons Attribution 4.0 International License, which permits use, sharing, adaptation, distribution and reproduction in any medium or format, as long as you give appropriate credit to the original author(s) and the source, provide a link to the Creative Commons licence, and indicate if changes were made. The images or other third party material in this article are included in the article's Creative Commons licence, unless indicated otherwise in a credit line to the material. If material is not included in the article's Creative Commons licence and your intended use is not permitted by statutory regulation or exceeds the permitted use, you will need to obtain permission directly from the copyright holder. To view a copy of this licence, visit http://creativecommons.org/licenses/by/4.0/ The Creative Commons Public Domain Dedication waiver (http://creativecommons.org/publicdomain/zero/1.0/) applies to the data made available in this article, unless otherwise stated in a credit line to the data. 


\section{Background}

Postpartum Depression (PPD) refers to non-psychotic depressive episodes that begin in or extend into the postpartum period [1]. According to The American Psychiatric Association (APA) postpartum depression is defined as the occurrence of a Major Depressive Episode (MDE) within 4 weeks after delivery [2].

About 14\% of the worldwide burden of disease has been attributed to neuropsychiatric disorders, including those disorders that can occur during the postpartum period. Such estimates have drawn attention to the importance of mental disorders for public health [3]. The estimated lifetime prevalence of having one or more of the mental disorders varies widely across the world as shown by mental health surveys, from $12.1 \%$ in Nigeria to $47.4 \%$ in the United [4].

Postpartum depression is a non-psychotic depressive disorder that affects 13 to $19 \%$ of postpartum women and those women experience signs and symptoms like self-blaming thought, guilt about their inability to look after their new baby, low self-esteem, lack of interest in one's environment, insecurity and suicidal thoughts. This condition begins in the postpartum period and persists up to a one-year duration after delivery. The treatment option for PPD women is behavioral counseling and anti-depressant therapy [2, 5-7].

World Health Organization (WHO) reported that for women of reproductive age group depression becomes the leading cause of disease burden [8]. Postpartum nonpsychotic depression is a considerable public health problem and the most common complication of childbearing age that affect approximately $10-15 \%$ of postpartum women. In developing countries, the prevalence of postpartum depression almost doubled that of the developed world. The effect of postpartum depression on the mother, her marital relationship and her children make it an important condition to diagnose, treat and prevent $[9,10]$. Untreated postpartum depression can have a prolonged adverse effect on the mother and her children. Pregnant mothers' ongoing depression can contribute to emotional, behavioral, cognitive and interpersonal problems [11].

Epidemiological studies conducted in China, Japan, India and New Dubai Hospital in Dubai, revealed that the overall prevalence of postpartum depression was 13.5, 17, 23, and $15.8 \%$ respectively [12-15]. Another quasi-experimental study conducted among 420 consenting pregnant women on the title of postpartum depression in peri-urban communities of Karachi, Pakistan, revealed that the overall prevalence of postpartum depression was $28.8 \%$ [16]. The growth of the child is potentially affected in response to the potential decline in care by the mother experienced PPD. Determining the prevalence of postpartum depression, and identifying associated factors with it is important to show the magnitude of the problem. This study aimed to determine the prevalence of postpartum depression in the study area and to identify associated factors of postpartum depression.

\section{Specific objectives}

- To determine the prevalence of postpartum depression in postnatal care attendees

- To identify factors associated with postpartum depression in postnatal care attendees.

\section{Methods}

\section{The study area, design and period}

The study was conducted in Debre Berhan town which found in the North Shoa zone at Amhara regional state of Ethiopia. This town is found $130 \mathrm{~km}$ away from the capital city of Ethiopia; Addis Ababa. The cross-sectional study design was employed from 1st May to June 30, 2018. The study site had a total of one government-owned referral hospital, three health centers, five private clinics, and more than ten pharmacies. There were 613 mothers who gave birth and attended postpartum care and vaccination service during the study period.

\section{Population}

Source Population: All women who came for postnatal care and vaccination services within 6 weeks after delivery in a referral hospital and health centers in Debre Berhan, Town Ethiopia.

Study Population: All women who came for postnatal care and vaccination service within 6 weeks after delivery during the data collection period.

\section{Eligibility \\ Inclusion Criteria}

All women who gave birth and who came for postnatal care and vaccination service within 6 weeks after delivery in health centers and referral hospital were included.

\section{Exclusion Criteria}

Women who had a verbal communication problem and complete loss of hearing were excluded.

\section{Sample size calculation and sampling technique}

The required sample size was determined by using a single population proportion formula with the following assumptions: $(\mathrm{Z} \alpha / 2)=$ value for the $95 \% \mathrm{CI},=1.96$, the proportion of postpartum depression; similar study at Gondar, Ethiopia $(P=23 \%)$ [17], $\mathrm{d}=$ margin of error taken as $5 \%$; by adding $10 \%$ of study subjects as nonresponse rate, the final sample size became 308 . The study subjects were interviewed by using systematic random sampling after determining the sampling fraction $(k=613 / 308=2)$ and the first participant was selected by using the lottery method. The total sample size $(n=308)$ was allocated proportionally according to the total number of postpartum care and vaccination service attendees at each health center (district 04, district 07, district 08) and Debre Berhan referral hospital. 


\section{Study variables \\ Dependent variable \\ Postpartum Depression (yes/no).}

\section{Independent variables}

Socio-demographic factors: (age, educational status, economic, marital status, employment, monthly income, current residence).

Social factors: - social and husband support, emotional violence, physical violence, sexual violence.

Substance use: use of any substance during the puerperium period for a non-medical purpose (like Khat, alcohol, and cigarette).

Obstetrics factors: parity, pregnancy intention, currently a hospitalized child, mode of delivery, perinatal complication or illness, stressful life event during the puerperium period and undesired fetal sex.

Previous psychiatric history: A family history (first-degree relatives) of psychiatric problems.

\section{Operational definitions \\ Poor social support}

Mothers who scored 3-8 on the (Oslo-3) social support scale during puerperium.

\section{Moderate social support}

Mothers who scored 9-11 on the (Oslo-3) social support scale during puerperium.

\section{Strong social support}

Mothers who scored $11-14$ on the (Oslo-3) social support scale during puerperium.

\section{Data collection tools and procedures}

A structured interviewer-administered questionnaire was used to collecting information from study participants. Sociodemographic, clinical, and obstetric factors were assessed by predefined checklists. The social support level was assessed by using the Oslo social support scale, and the Edinburgh Postnatal Depression Scale (EPDS) was used to assess postpartum depression. Data were collected with an interviewer-administered questionnaire from mothers who came for postnatal care and vaccination service.

\section{Data quality control and analysis}

The data collection instrument was pre-tested on $5 \%$ of the sample size out of Debre Berhan town to improve language clarity and appropriateness of data collection tools. The estimated time required, and necessary amendments were made after the piloting of the questionnaire. Four fourth-year undergraduate nursing students collected the data. The data collectors were trained for 1 day on the techniques of data collection. The training also included the importance of disclosing the possible benefit and purpose of the study to the study participants before the start of data collection. The researcher checked completeness and consistency of questionnaires filled by the data collectors to ensure the quality of data and also visited the data collectors as many times as possible to check whether he/she collected the data appropriately. The collected data were entered into Epi-info version 7 and analysis was done after the data were imported to SPSS version 20. During bivariate analysis, variables with $p$-value $<0.05$ were exported to multivariate analysis. Crude and adjusted odds ratios were analyzed using bivariate and multivariable binary logistic regression analysis and the level of significance of association was determined at $\mathrm{p}$-value $<0.05$.

\section{Results}

Socio-demographic characteristics of postpartum mothers There were 613 mothers who gave birth and attended postpartum care and vaccination service during the study period. Among them, 308 mothers were included in the study by using systematic random sampling technique, which was a $100 \%$ response rate. Among the study subjects, 286 (86\%) were aged 25-45 years and almost $85 \%$ were married. The majority of the participants, 206(66.9\%) had attended formal (modern) education. Regarding ethnicity, the majority of the study participants, 234(76\%) were Amhara and 62(20.1\%) were Oromo. Two hundred sixty-eight $(87 \%)$ of the participants earn a monthly income greater than 2500 Ethiopian Birr. Almost $60 \%$ of the participant's religion, 191(62\%) were orthodox Christian followers (Table 1).

\section{Obstetric and clinical characteristic of postpartum mothers}

From 308 study participants, the majority of respondents $254(82.5 \%)$ were multigravida (give birth $>1$ ) and $54(17.5 \%)$ were primigravida (having a first child). Almost $80 \%$ of participants had two or more living children during the study period. Regarding termination of pregnancy, 53(17.2\%) had experienced termination and $39(12.7 \%)$ had experienced the death of their child. Forty-eight (15.6\%) participants reported that the recent pregnancy was unplanned. Moreover, the sex of the last baby $189(61.4 \%)$ were male and the rest were female. Regarding the desired sex of the last baby, 36(11.7\%) of the respondents said that the sex of their infant was unwanted gender. Nearly $62 \%$ of participants, $190(61.7 \%)$ mode of delivery was a spontaneous vaginal delivery. Forty-seven, 47(15.3\%) respondents had suffered from any diagnosed illness during their last pregnancy and 95(30.8\%) study mothers reported their babies were admitted to the hospital at least once before (Table 2). 
Table 1 Socio-demographic characteristics of mothers who have postnatal care at Debre Berhan health centers and referral hospital, 2018

\begin{tabular}{|c|c|c|c|}
\hline Variables & Category & Frequency & Percentage \\
\hline \multirow[t]{2}{*}{ Age in years } & $19-24$ & 43 & 14.0 \\
\hline & $25-45$ & 265 & 86.0 \\
\hline \multirow[t]{3}{*}{ Marital status } & Single & 28 & 9.1 \\
\hline & Widowed/widower & 19 & 6.2 \\
\hline & Married & 261 & 84.7 \\
\hline \multirow[t]{2}{*}{ Address } & Urban & 215 & 69.8 \\
\hline & Rural & 93 & 30.2 \\
\hline \multirow[t]{4}{*}{ Religion } & Orthodox & 191 & 62.0 \\
\hline & Catholic & 15 & 4.9 \\
\hline & Muslim & 47 & 15.3 \\
\hline & Protestant & 55 & 17.9 \\
\hline \multirow[t]{3}{*}{ Ethnicity } & Amhara & 234 & 76.0 \\
\hline & Oromo & 62 & 20.1 \\
\hline & Tigray & 12 & 3.9 \\
\hline \multirow[t]{2}{*}{ Attended modern education } & Yes & 206 & 66.9 \\
\hline & No & 102 & 33.1 \\
\hline \multirow[t]{5}{*}{ Occupational status of mother } & Government employed & 84 & 27.2 \\
\hline & House wife & 146 & 47.4 \\
\hline & private employed & 58 & 18.8 \\
\hline & Farmer & 8 & 2.6 \\
\hline & Unemployed & 12 & 3.9 \\
\hline \multirow[t]{3}{*}{ Monthly income } & $\leq 1200$ & 5 & 1.6 \\
\hline & $1201-2500$ & 35 & 11.4 \\
\hline & $\geq 2501$ & 268 & 87.0 \\
\hline
\end{tabular}

\section{Psychosocial factors (in last 6 months) of postpartum} mothers

From the total study participants, 62(20.1\%) responded that their family or a close relative had died. Almost one fifth (19.5\%), participants reported that there was a serious illness, injury or assault during the recent pregnancy. Almost 60, 59(19.2\%) study participants had experienced parent or child death and 42(13.6\%) participants reported that they were separated due to marital difficulty. In addition, 41(13.7\%) study participants were unemployed / not been able to work in the last 6 months of the study period. Moreover, 40(13\%) reported physical violence during the last pregnancy (Table 3 ).

\section{Substance use among postpartum mothers}

Overall, 31(10.1\%) of study participants reported the use of any substance before pregnancy and of these the majority of use was alcohol-related; i.e. 21(67.7\%). The remaining used only Khat at least once in a lifetime. Regarding substance used during the last pregnancy, $18(5.8 \%)$ respondents used any kind of substance, and all of them used alcohol.
History of known illness among postpartum mothers

Of the total study participants, 31(10.1\%) had a known history of mental illness. In addition, 44(14.3\%) study respondents had a family history of known mental illness and 28(9.1\%) had diagnosed diabetes mellitus and hypertension.

\section{Social support among postpartum mothers}

Social support status was assessed by using the Oslo-3 social support scale. From the total study participants, the majority $137(44.5 \%)$ had moderate social support, 114(37\%) had poor social support and the rest had strong social support. During pregnancy, 175(56.8\%), 111(36\%), and $22(7.1 \%)$ had strong, moderate, and poor husband support respectively. Thirty-six percent, 112(36.4\%) study participants had no practical support from a family member during pregnancy (such as cooking, washing, cleaning or child-rearing), and during puerperium.

\section{Prevalence of postpartum depression and its associated} factors

According to the Edinburgh Postnatal Depression Scale (EDPS), study participants who scored $\geq 13$ are considered 
Table 2 Obstetric and clinical characteristic among mothers who have postnatal care, Debre Berhan, Ethiopia, 2018

\begin{tabular}{|c|c|c|c|}
\hline Variable & Category & Frequency & Percent \% \\
\hline \multirow[t]{2}{*}{ Number of pregnancy } & 1 & 54 & 17.5 \\
\hline & $\geq 2$ & 254 & 82.5 \\
\hline \multirow[t]{2}{*}{ Living child } & 1 & 64 & 20.8 \\
\hline & $\geq 2$ & 244 & 79.2 \\
\hline \multirow[t]{2}{*}{ Sex of last baby } & Male & 189 & 61.4 \\
\hline & Female & 119 & 38.6 \\
\hline \multirow[t]{2}{*}{ Desired sex of the baby } & Desired & 271 & 71.3 \\
\hline & Undesired & 109 & 28.7 \\
\hline \multirow[t]{2}{*}{ Abortion } & Yes & 25 & 6.6 \\
\hline & No & 355 & 93.4 \\
\hline \multirow[t]{2}{*}{ Pattern of pregnancy termination } & Spontaneous & 47 & 15.3 \\
\hline & Induced & 6 & 1.9 \\
\hline \multirow[t]{2}{*}{ Number of termination of pregnancy } & 1 & 49 & 15.9 \\
\hline & $\geq 2$ & 4 & 1.3 \\
\hline \multirow[t]{2}{*}{ Baby death } & Yes & 38 & 10.0 \\
\hline & No & 342 & 90.0 \\
\hline \multirow[t]{2}{*}{ Had a current hospitalized baby } & Yes & 95 & 30.8 \\
\hline & No & 213 & 69.2 \\
\hline \multirow[t]{3}{*}{ Mode of delivery } & Vaginal & 190 & 61.7 \\
\hline & Cesarean section & 87 & 28.2 \\
\hline & Vacuum/forceps & 31 & 10.1 \\
\hline \multirow[t]{2}{*}{ Planed pregnancy } & Yes & 260 & 84.4 \\
\hline & No & 48 & 15.6 \\
\hline \multirow[t]{2}{*}{ IIIness/complication in last pregnancy } & Yes & 47 & 12.4 \\
\hline & No & 333 & 87.6 \\
\hline
\end{tabular}

as having postpartum depression. Hence, the prevalence of postpartum depression among mothers who have postnatal care follow up was $15.6 \%$ [95\% CI $=11.7,19.8]$.

Binary logistic regression was performed to assess the association of each independent variable with the outcome variable (postpartum depression). The variables that showed a significance level $(p<0.05)$ during bivariate analysis were added to the multivariate regression model. Twenty-two independent variables were shown to be significantly associated during the bivariate analysis. The result of the multivariate analysis showed that only four variables were statistically significant. Being widowed/widower, having a current hospitalized child, having died family or close relative, having poor social support showed a significant association with postpartum depression.

The results showed that women who were widowed/ widower had an association with postpartum depression; and were four times more likely to experience postpartum depression than those who were married $[\mathrm{AOR}=$ $4.17,95 \% \mathrm{CI}=1.14,15.20]$. In addition, respondents who had poor social support were five times more likely to be depressed than those who had strong social support $[\mathrm{AOR}=5.11,95 \% \mathrm{CI}=1.00,26.18]$. Respondents who had a current hospitalized children were nearly 3 times more likely to be depressed as compared to respondents who does not have a current hospitalized child $[\mathrm{AOR}=$ $3.32,95 \% \mathrm{CI}=1.39,7.93]$. In a similar dimension, participants who had experienced a death of a family member or close relative in the last 6 months were three times more likely to be depressed than those who did not experience this $[\mathrm{AOR}=2.92,95 \% \mathrm{CI}=1.01,8.50]$, $($ Table 4$)$.

\section{Discussion}

\section{Prevalence of postpartum depression}

There were 613 mothers who gave birth and attended postpartum care and vaccination service during the study period. Among them, 308 mothers were included in the study by using systematic random sampling technique $(k=2)$, which was a $100 \%$ response rate. The overall prevalence of postpartum depression was $15.6 \%(95 \% \mathrm{CI}=11.7,19.8)$. 
Table 3 Psychosocial characteristic (in last 6 months) among mothers who have postnatal care, Debre Berhan, Ethiopia, 2018

\begin{tabular}{|c|c|c|c|}
\hline Variable & Category & Frequency & Percent (\%) \\
\hline \multirow[t]{2}{*}{ Serious illness injury or assault during pregnancy } & Yes & 42 & 13.6 \\
\hline & No & 266 & 86.4 \\
\hline \multirow[t]{2}{*}{ Close relative serious illness, injury or assault } & Yes & 60 & 19.5 \\
\hline & No & 248 & 80.5 \\
\hline \multirow[t]{2}{*}{ Died spouse, parent or child } & Yes & 59 & 19.2 \\
\hline & No & 249 & 80.8 \\
\hline \multirow[t]{2}{*}{ Died Family or close relative } & Yes & 62 & 20.1 \\
\hline & No & 246 & 79.9 \\
\hline \multirow[t]{2}{*}{ Major financial crisis } & Yes & 37 & 12.0 \\
\hline & No & 271 & 88.0 \\
\hline \multirow[t]{2}{*}{ Sacked from job } & Yes & 12 & 3.9 \\
\hline & No & 296 & 96.1 \\
\hline \multirow[t]{2}{*}{ Unemployed/not able to work } & Yes & 41 & 13.3 \\
\hline & No & 267 & 86.7 \\
\hline \multirow[t]{2}{*}{ Separation due to marital difficulty } & Yes & 42 & 13.6 \\
\hline & No & 266 & 86.4 \\
\hline \multirow[t]{2}{*}{ Broken off a steady relationship } & Yes & 33 & 10.7 \\
\hline & No & 275 & 89.3 \\
\hline \multirow[t]{2}{*}{ Serious problem with close friend, neighbor /relative } & Yes & 37 & 12 \\
\hline & No & 271 & 88 \\
\hline \multirow[t]{2}{*}{ Lost / stolen property which mattered a lot } & Yes & 30 & 9.7 \\
\hline & No & 278 & 90.3 \\
\hline \multirow[t]{2}{*}{ Any problems with police/court } & Yes & 18 & 5.8 \\
\hline & No & 290 & 94.2 \\
\hline \multirow[t]{2}{*}{ Emotional violence } & Yes & 26 & 8.4 \\
\hline & No & 282 & 91.6 \\
\hline \multirow[t]{2}{*}{ Physical violence } & Yes & 40 & 13 \\
\hline & No & 268 & 87 \\
\hline \multirow[t]{3}{*}{ Who physically violate you } & Boy friend & 21 & 52.5 \\
\hline & Family member & 8 & 20 \\
\hline & Stranger & 11 & 27.5 \\
\hline \multirow[t]{2}{*}{ Forced sexual activity } & Yes & 35 & 11.4 \\
\hline & No & 273 & 88.6 \\
\hline \multirow[t]{3}{*}{ Who forced you for sexual activity } & Boy friend & 15 & 37.5 \\
\hline & Family member & 2 & 5 \\
\hline & Stranger & 18 & 45 \\
\hline
\end{tabular}

This was almost similar to other studies that were conducted in Delhi and adjacent states of northern India, $15.8 \%$ [18], Egypt, 17.9\% [19], and Uganda, 16.3\% [20].

The prevalence rates were higher in our study when compared with Canadian, Denmark, and Uganda (Kampala), and Egypt study which was 1.6, 5.5 and 6.1\%, 7.14\% respectively [21-24]. The higher rate might be due to the use of different measurement tools, assessment period, social support level and economic status of the mothers.
On the other hand, this figure was lower when compared with other similar studies done in Lebanon, $21 \%$ [25], Cameroon, 23.4\% [26], Nigeria, 23\% [27]. The lower prevalence rate in our study might be due to difference in residency, and sample size difference. For instance, the study in Lebanon was conducted in a rural area by using a follow-up study with a sample size of 396 mothers. In addition, the study conducted in Cameroon used a case-control study design while our 
Table 4 Bivariate and multivariate analysis of factors associated postpartum depression among mothers who have postnatal care, Debre Berhan, Ethiopia, 2018

\begin{tabular}{|c|c|c|c|c|c|}
\hline \multirow[t]{2}{*}{ Variables } & & \multicolumn{2}{|c|}{ Postpartum Depression } & \multirow[t]{2}{*}{ COR $(95 \% \mathrm{Cl})$} & \multirow[t]{2}{*}{$\mathrm{AOR}(95 \% \mathrm{Cl})$} \\
\hline & & $\overline{\text { Yes }}$ & No & & \\
\hline \multirow[t]{3}{*}{ Marital status } & Single & 10 & 18 & $4.28(1.81,10.13)$ & $2.70(0.72,10.21)$ \\
\hline & Widowed/widower & 8 & 11 & $5.60(2.09,15.03)$ & $4.17(1.14,15.20)^{*}$ \\
\hline & Married & 30 & 231 & 1.00 & 1.00 \\
\hline \multirow[t]{2}{*}{ Attend modern school } & Yes & 24 & 182 & 1.00 & 1.00 \\
\hline & No & 24 & 78 & $2.33(1.25,4.36)$ & $0.76(0.34,1.71$ \\
\hline \multirow[t]{3}{*}{ Social support } & Poor & 34 & 80 & $11.69(2.70,50.67)$ & $5.11(1.00,26.18)^{*}$ \\
\hline & Moderate & 12 & 125 & $2.64(0.57,12.19)$ & $1.93(0.36,10.36)$ \\
\hline & Strong & 2 & 55 & 1.00 & 1.00 \\
\hline \multirow[t]{3}{*}{ Husband support } & Poor & 8 & 14 & $4.43(1.65,11.8)$ & $0.70(0.14,3.57)$ \\
\hline & Moderate & 20 & 91 & $1.70(0.870,3.33)$ & $1.02(0.42,2.47$ \\
\hline & Strong & 20 & 155 & 1.00 & 1.00 \\
\hline \multirow[t]{2}{*}{ Serious illness, injury or assault to a close relative } & Yes & 17 & 43 & $2.77(1.41,5.44)$ & $0.28(0.08,10.96)$ \\
\hline & No & 31 & 217 & 1.00 & 1.00 \\
\hline \multirow[t]{2}{*}{ Died spouse, parent or child } & Yes & 20 & 39 & $4.05(2.08,7.89$ & $0.56(0.17,1.85$ \\
\hline & No & 28 & 221 & 1.00 & 1.00 \\
\hline \multirow[t]{2}{*}{ Died close family or relative } & Yes & 21 & 41 & $4.15(2.15,8.04)$ & $2.92(1.01,8.50)^{*}$ \\
\hline & No & 27 & 219 & 1.00 & 1.00 \\
\hline \multirow[t]{2}{*}{ Has major financial crisis } & Yes & 14 & 23 & $4.24(1.99,9.03)$ & $1.74(0.55,5.49$ \\
\hline & No & 34 & 237 & 1.00 & 1.00 \\
\hline \multirow[t]{2}{*}{ Sacked from job } & Yes & 5 & 7 & $4.20(1.28,13.85$ & $0.67(0.21,2.11)$ \\
\hline & No & 43 & 253 & 1.00 & 1.00 \\
\hline \multirow[t]{2}{*}{ Unemployed/not able to work } & Yes & 15 & 26 & $4.09(1.97,8.51)$ & $3.21(0.68,15.12)$ \\
\hline & No & 33 & 234 & 1.00 & 1.00 \\
\hline \multirow[t]{2}{*}{ Separation due to marital difficulty } & Yes & 13 & 29 & $2.96(1.40,6.23)$ & $0.72(0.22,2.40)$ \\
\hline & No & 35 & 231 & 1.00 & 1.00 \\
\hline \multirow[t]{2}{*}{ Broken off steady friendship/relationship } & Yes & 14 & 19 & $5.22(2.40,11.37)$ & $0.75(0.22,2.50)$ \\
\hline & No & 34 & 241 & 1.00 & 1.00 \\
\hline \multirow[t]{2}{*}{ Serious problem with close friend, neighbor /relative } & Yes & 13 & 24 & $3.65(1.70,7.83)$ & $1.86(0.51,6.81)$ \\
\hline & No & 35 & 236 & 1.00 & 1.00 \\
\hline \multirow[t]{2}{*}{ Any problems with police/court } & Yes & 6 & 12 & $2.95(1.05,8.30)$ & $0.62(0.19,2.05)$ \\
\hline & No & 42 & 248 & 1.00 & 1.00 \\
\hline \multirow[t]{2}{*}{ Emotional/physical abused by parents } & Yes & 9 & 17 & $3.30(1.37,7.92)$ & $1.51(0.47,4.90)$ \\
\hline & No & 39 & 243 & 1.00 & 1.00 \\
\hline \multirow[t]{2}{*}{ Had a current hospitalized baby } & Yes & 27 & 68 & $3.63(1.926,6.84)$ & $3.32(1.39,7.93)^{*}$ \\
\hline & No & 21 & 192 & 1.00 & 1.00 \\
\hline \multirow[t]{2}{*}{ Pregnancy intention } & Planned & 35 & 225 & 1.00 & 1.00 \\
\hline & Unplanned & 13 & 35 & $2.39(1.15,4.95)$ & $0.75(0.25,2.21)$ \\
\hline \multirow[t]{2}{*}{ Forced sexual activity } & Suffered & 13 & 22 & $4.02(1.86,8.69)$ & $2.00(0.68,5.93)$ \\
\hline & Not suffered & 35 & 238 & 1.00 & 1.00 \\
\hline
\end{tabular}


Table 4 Bivariate and multivariate analysis of factors associated postpartum depression among mothers who have postnatal care, Debre Berhan, Ethiopia, 2018 (Continued)

\begin{tabular}{|c|c|c|c|c|c|}
\hline \multirow[t]{2}{*}{ Variables } & & \multicolumn{2}{|c|}{ Postpartum Depression } & \multirow[t]{2}{*}{ COR $(95 \% \mathrm{Cl})$} & \multirow[t]{2}{*}{$\mathrm{AOR}(95 \% \mathrm{Cl})$} \\
\hline & & Yes & No & & \\
\hline \multirow[t]{2}{*}{ Diagnosed mental illness in the family } & Yes & 15 & 29 & $3.62(1.76,7.46$ & $2.04(0.68,6.14)$ \\
\hline & No & 33 & 231 & 1.00 & 1.00 \\
\hline \multirow[t]{2}{*}{ Diabetes mellitus } & Yes & 12 & 16 & $5.08(2.23,11.6)$ & $2.40(0.69,8.35)$ \\
\hline & No & 36 & 244 & 1.00 & 1.00 \\
\hline
\end{tabular}

Key: ${ }^{*}=p$-value less than $0.05 ; C O R$ crude odds ratio, $A O R$ adjusted odds ratio, $C l$ confidence interval

study used a cross-sectional study design. Similar studies in Ethiopia revealed that 22.1\% [28], 22.4\% [29], 31.5\% [30], of mothers were depressed during puerperium. These studies had higher prevalence rates than our study. The higher prevalence report in these studies might be due to the screening tool, study design, and sample size. The study done in the Oromia region used a self-reporting questionnaire (SRQ) and a community-based cross-sectional study.

\section{Factors associated with postpartum depression}

Among the sociodemographic factors, study subjects who were widowed/widower had an association with postpartum depression: almost four times higher when compared with those who were married. In this cohort, the association was in agreement with the study done in Ethiopia [31]. The agreement might be due to the fact that being married is important for mental health; especially during the postpartum period.

In the social support dimension, respondents who had poor social support were more likely to be depressed than those who had strong social support. The association in estimation was in line with studies done in Malaysian and Pakistan [32], Cameroon; Yaoundé [26] and Hiwot Fana specialized University Hospital in Ethiopia [10]. In fact, having poor social support is one of the highest contributors to poor mental health [33].

The variables that were found to have an association with postpartum depression were having a hospitalized child during the postpartum period. Respondents who had a current hospitalized child were almost three times more likely to be depressed as compared to the respondent who had not a current hospitalized child. In a similar dimension, participants who had experienced a death of a family member or close relative in the last 6 months were three times more likely to have postpartum depression than those who does not experienced a death of a family member or close relative. The association was in agreement with the study done in Robe town; Bale Zone, Ethiopia [30]. The possible reason might be due to the fact that experiencing life-threatening events during the postpartum period became intolerable and may affect the mental wellness of the mothers.

\section{Limitations}

Postpartum women with persisting depression already acquired before/during pregnancy were not excluded and this may further increase the prevalence rates of postpartum depression. The study only included mothers who had postnatal care follow up in the urban area. Since we recruited multiple data collectors, there may be interviewer bias.

\section{Conclusions}

Though significant proportions of postnatal mothers had depression, the prevalence of postpartum depression was lower than most studies in different areas. Major life events and trauma are associated with an increased risk of postpartum depression. Health professionals should be aware of the mother's circumstances during pregnancy. They should initiate support to reduce the risk of depression in the postpartum period. Health care professionals working in maternal and child health clinics should give special attention to pregnant mothers who are widowed/widower, have poor social support, have a current hospitalized child, and experienced a death of a family member or close relative.

\section{Recommendations}

It would be advisable if midwife professionals routinely screen postpartum depressive symptoms and link them to mental health services just like other reproductive health problems for mothers attending hospitals and health centers after delivery.

\section{Acknowledgments}

Our thanks dedicated to Debre Berhan University and AMARI project. Kefyalew Dagne was supported through AMARI (Africa mental health research initiative) which is funded through the DELTAS Africa initiative (DEL-15-01).

\section{Authors' contributions}

$A D$ and NA: Analyzed the data and write up the thesis report and the manuscript. KD: selected the title and develop the proposal. All the authors read and approved the final manuscript and agreed to be accountable for all aspects of the work.

\section{Funding}

This study was not supported by any grant. Funding for data collection, entry, analysis and write-ups were provided by the authors.

\section{Availability of data and materials}

The datasets used and/or analyzed during the current study are available from the corresponding author on reasonable request. 


\section{Ethics approval and consent to participate}

Ethical clearance was obtained from the Debre Berhan University ethical review board (IRB). Permission letter to each study health institution was written and permission letter was taken.

Written informed consent was taken from each study participant.

\section{Consent for publication}

The manuscript did not contain individuals' person detailed data in any form.

\section{Competing interests}

The authors declare that they have no competing interests.

Received: 10 September 2019 Accepted: 10 March 2020

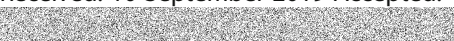

\section{References}

1. O'Hara MW. Postpartum depression: what we know. J Clin Psychol. 2009; 65(12):1258-69.

2. Association AP. Diagnostic and statistical manual of mental disorders (DSM$\left.5^{\oplus}\right)$ : American psychiatric pub; 2013

3. Johnson J, Weissman MM, Klerman GL. Service utilization and social morbidity associated with depressive symptoms in the community. Jama. 1992:267(11):1478-83.

4. Kessler RC, Angermeyer M, Anthony JC, De Graaf R, Demyttenaere K, Gasquet I, et al. Lifetime prevalence and age-of-onset distributions of mental disorders in the World Health Organization's world mental health survey initiative. World Psychiatry. 2007;6(3):168.

5. Bennett HA, Einarson A, Taddio A, Koren G, Einarson TR. Prevalence of depression during pregnancy: a systematic review. Obstet Gynecol. 2004;103(4):698-709.

6. Evans J, Heron J, Patel RR, Wiles N. Depressive symptoms during pregnancy and low birth weight at term. Br J Psychiatry. 2007;191(1):84-5.

7. Health NCCFM. Depression in children and young people: identification and management in primary, community and secondary care. Database of Abstracts of Reviews of Effects (DARE): Quality-assessed Reviews [Internet]: Centre for Reviews and Dissemination (UK); 2005.

8. Organization WH. The global burden of disease: 2004 update. Geneva: WHO; 2008. p. 2017

9. Stewart DE, Robertson E, Dennis C-L, Grace SL, Wallington T. Postpartum depression: literature review of risk factors and interventions. Toronto: University Health Network Women's Health Program for Toronto Public Health; 2003.

10. Shewangzaw A, Tadesse B, Ashani T, Misgana T, Shewasinad S. Prevalence of postpartum depression and associated factors among postnatal women attending at Hiwot Fana Specialized University hospital, Harar, East Ethiopia, 2015/2016. Open Access J Reproductive Syst Sexual Disorders. 2018;1(1):4-19.

11. Jacobsen T. Effects of postpartum disorders on parenting and on offspring. Miller J Perinatal Med. 1999:39(5):515-21.

12. Ghubash R, Abou-Saleh M. Postpartum psychiatric illness in Arab culture: prevalence and psychosocial correlates. Br J Psychiatry. 1997;171(1):65-8.

13. Lee DT, Yip AS, Chiu HF, Leung TY, Chung TK. A psychiatric epidemiological study of postpartum Chinese women. Am J Psychiatr. 2001;158(2):220-6.

14. Yoshida K, Yamashita $\mathrm{H}$, Ueda M, Tashiro N. Postnatal depression in Japanese mothers and the reconsideration of 'Satogaeri bunben'. Pediatr Int. 2001;43(2):189-93.

15. Patel V, Rodrigues M, DeSouza N. Gender, poverty, and postnatal depression: a study of mothers in Goa, India. Am J Psychiatr. 2002:159(1):43-7.

16. Ali NS, Ali BS, Azam IS. Post partum anxiety and depression in peri-urban communities of Karachi, Pakistan: a quasi-experimental study. BMC Public Health. 2009;9(1):384

17. Ayele TA, Azale T, Alemu K, Abdissa Z, Mulat H, Fekadu A. Prevalence and associated factors of antenatal depression among women attending antenatal care service at Gondar university hospital, Northwest Ethiopia. PLoS One. 2016:11(5):e0155125.

18. Gupta S, Kishore J, Mala Y, Ramji S, Aggarwal R. Postpartum depression in north Indian women: prevalence and risk factors. J Obstetrics Gynecol India. 2013;63(4):223-9.

19. Saleh E-S, El-Bahei W, del El-Hadidy MA, Zayed A. Predictors of postpartum depression in a sample of Egyptian women. Neuropsychiatr Dis Treat. 2013;9:15.
20. Kakyo TA, Muliira JK, Mbalinda SN, Kizza IB, Muliira RS. Factors associated with depressive symptoms among postpartum mothers in a rural district in Uganda. Midwifery. 2012;28(3):374-9.

21. Eberhard-Gran M, Eskild A, Tambs K, Samuelsen S, Opjordsmoen S. Depression in postpartum and non-postpartum women: prevalence and risk factors. Acta Psychiatr Scand. 2002;106(6):426-33.

22. Nielsen D, Videbech P, Hedegaard M, Dalby J, Secher NJ. Postpartum depression: identification of women at risk. BJOG Int J Obstet Gynaecol. 2000:107(10):1210-7.

23. Nakku JN, Nakasi G, Mirembe F. Postpartum major depression at six weeks in primary health care: prevalence and associated factors. African Health Sci. 2006;6(4).

24. Salem MN, Thabet MN, Fouly $H$, Abbas AM. Factors affecting the occurrence of postpartum depression among puerperal women in Sohag city, Egypt. Proc Obstetrics Gynecol. 2017:7(1):1-10.

25. Chaaya M, Campbell O, El Kak F, Shaar D, Harb H, Kaddour A. Postpartum depression: prevalence and determinants in Lebanon. Archives Women's Mental Health. 2002;5(2):65-72.

26. Adama ND, Foumane P, Olen JPK, Dohbit JS, Meka ENU, Mboudou E. Prevalence and risk factors of postpartum depression in Yaounde, Cameroon. Open J Obstetrics Gynecol. 2015;5(11):608.

27. Owoeye A, Aina O, Morakinyo O. Risk factors of postpartum depression and EPDS scores in a group of Nigerian women. Trop Dr. 2006;36(2):100-3.

28. Abebe A, Tesfaw G, Mulat H, Hibdye G. Postpartum depression and associated factors among mothers in Bahir Dar town, Northwest Ethiopia. Ann General Psychiatry. 2019;18(1):19.

29. Toru T, Chemir F, Anand S. Magnitude of postpartum depression and associated factors among women in Mizan Aman town, bench Maji zone, Southwest Ethiopia. BMC Pregnancy Childbirth. 2018;18(1):442.

30. Tefera TB, Erena AN, Kuti KA, Hussen MA. Perinatal depression and associated factors among reproductive aged group women at Goba and Robe Town of Bale Zone, Oromia Region, South East Ethiopia. Maternal Health Neonatol Perinatol. 2015;1(1):12.

31. Bitew T. Prevalence and risk factors of depression in Ethiopia: a review. Ethiop J Health Sci. 2014:24(2):161-9.

32. Klainin P, Arthur DG. Postpartum depression in Asian cultures: a literature review. Int J Nurs Stud. 2009:46(10):1355-73.

33. Kessler RC, McLeod JD. Social support and mental health in community samples. In S. Cohen \& SL Sume (Eds). Social support and health. New York: Academic Press; 1985

\section{Publisher's Note}

Springer Nature remains neutral with regard to jurisdictional claims in published maps and institutional affiliations.

Ready to submit your research? Choose BMC and benefit from:

- fast, convenient online submission

- thorough peer review by experienced researchers in your field

- rapid publication on acceptance

- support for research data, including large and complex data types

- gold Open Access which fosters wider collaboration and increased citations

- maximum visibility for your research: over $100 \mathrm{M}$ website views per year

At $\mathrm{BMC}$, research is always in progress.

Learn more biomedcentral.com/submissions 